\title{
Twins Reared Apart and Twins in Families: The Findings Behind the Fascination
}

\author{
Nancy L. Segal, ${ }^{1}$ Yesika S. Montoya, ${ }^{2}$ and Erika N. Becker ${ }^{1}$ \\ ${ }^{1}$ Psychology Department, California State University, Fullerton, CA, USA \\ ${ }^{2}$ School of Social Work, Columbia University, New York, NY, USA
}

Dr. Irving I. Gottesman was very creative in applying twin research designs to test hypotheses and predictions about human behavior. Two designs stand out among others: twins reared apart from birth and the twin-family study. I (NS) was inspired to incorporate both of these approaches into my own research programs at California State University, Fullerton. Gottesman's involvement and contributions to reared-apart twin research are described, followed by selected findings from the Minnesota Study of Twins Reared Apart (MISTRA), the Fullerton Study of Chinese Twins Reared Apart (CTA), a case report on separated monozygotic (MZ) female twins from South Korea, and doubly exchanged MZ male twin pairs from Colombia, South America. Recent findings from an ongoing twin-family study of social closeness, and future directions, are also presented.

Keywords: twins reared apart, twin-family study, Chinese twins, Colombian twins, switched at birth

Twins reared apart from birth are a rare unplanned experiment, allowing unique insights into genetic and environmental factors underlying human behavior. Such studies are an informative variation of the classic monozygotic (MZ)dizygotic (DZ) twin comparison. That is because similarities between reared-together twins may reflect both shared genes and shared environments, whereas similarities between reared-apart twins offer direct estimates of genetic influence (Segal, 2012). The origins, methods, findings, and implications from four major reared-apart twin studies are available in comprehensive volumes published when these studies concluded (Juel-Nielsen, 1965; 1980; Newman et al., 1937; Segal, 2012; Shields, 1962). Results from other rearedapart twin projects have also been reported in the scientific literature (see, e.g., Kendler et al., 2000; Zhou et al., 2015). Gottesman was intensely interested in the research possibilities offered by reared-apart twins and made significant contributions in this regard.

Accidentally exchanged twins are a rare subgroup of separated twins, with only nine documented cases world-wide. The complete chronology of these pairs is summarized in Table 1. Of particular interest is the most recent case involving a double exchange between two pairs of $\mathrm{MZ}$ male twins from Colombia, South America. This event generated a series of genetically and environmentally informative kinships, some familiar, but some unique. Familiar sibling sets are two reared-apart MZ (MZA) twin pairs raised in dramatically different environments. The unique sibling pairs include: (a) two virtual twin pairs (same-age unrelated siblings) who believed they were DZ twins and were raised as such; and (b) two pairs of 'replicas' (unrelated siblings who were not reared together, but who genetically replicated the unrelated reared-together pairs); comparing replicas with virtual twins yields a measure of shared environmental influence. Gottesman was fascinated by this situation and was instrumental in making some Spanish protocols available as I (NS) prepared to visit Colombia to study these twins. A book detailing the life histories, physical development, and behavioral traits of these twins, Accidental Brothers, was dedicated to Irv (Segal \& Montoya, 2018).

\section{Twins Reared Apart}

In his 1980 introduction to Juel-Nielsen's Danish rearedapart twin study, Gottesman wrote, 'Amidst the furor created (Hearnshaw, 1979) by [Sir Cyril Burt's] fabrication of data, co-workers, and pairs of twins three genuinely classic studies of such rare pairs comprising much more than mere disembodied test scores for IQ have been ignored' (p. 7). His recognition of the investigatory power of reared-apart twins

ReCeIVEd 14 April 2018; ACCEPTEd 24 April 2018

ADDRESS FOR CORRESPONDENCE: Nancy L. Segal, Psychology Department, California State University, Fullerton, CA 92834, USA.E-mail: nsegal@fullerton.edu 


\section{TABLE 1}

Chronology of Switched-at-Birth Twin Pairs

\begin{tabular}{llll}
\hline Location & Date of birth & Gender & $\begin{array}{l}\text { Twins' age at } \\
\text { first meeting } \\
\text { in years }\end{array}$ \\
\hline Switzerland & 1941 & Male & 5 \\
Canada & 1971 & Male & 20 \\
Poland & 1983 & Female & 16 \\
Puerto Rico & 1985 & Female & 1.5 \\
Canary Islands (Spain) & 1973 & Female & 28 \\
Canary Islands (Spain) & Unknown & Male & Unknown \\
Colombia & 1988 & Male & 25 \\
\hline Cote: Sourced from & & &
\end{tabular}

Note: Sourced from Segal \& Montoya (2018).

a Double exchange: Switching of an identical twin from one pair with a fraternal twin from another pair.

${ }^{b}$ Double exchange: Switching of an identical twin from one pair with an identical twin from another pair.

is further evident in his subsequent remarks, also in the introduction: 'Identical twins brought up apart are scarce, indeed, and their potential for stimulating research ideas about the origins of normal and abnormal characteristics is great' (p. 9). He shared these views with his close colleague James Shields, who conducted the second reared-apart twin study in Great Britain in 1962. 'I doubt if MZAs will ever be more numerous and representative enough to provide the main evidence about environment, or about genetics, but they furnish critical examples of persons of identical genotype reared in different homes. They can give unique real-life illustrations of some of the many possible pathways from genes to human behavior - and so will always be of human and scientific interest' (Shields, 1978, p. 92).

Gottesman was a faculty member at the University of Minnesota in 1979 when Dr. Thomas J. Bouchard, Jr. invited newly reunited MZA twins, Jim Lewis and Jim Springer, to his laboratory for several days of intensive psychologi$\mathrm{cal}$ and medical assessment. The idea of a reared-apart twin study had been in the air prior to the discovery of the 'Jim twins', but Bouchard was not optimistic about identifying a sufficiently large sample of separated sets. However, the media attention surrounding the Jim twins attracted other participants, and when the study concluded in 1999, a total of 137 pairs (81 MZA and $56 \mathrm{DZA}$ ) had been assessed (Segal, 2012).

Gottesman was closely involved with this study despite his absence from Minnesota during the years 1980-2001. He co-authored papers on personality (Markon et al., 2002), intelligence (Johnson et al., 2004), and twin methodology (Johnson et al., 2009), but his signature contributions are two papers on the Minnesota Multiphasic Personality Inventory (MMPI) scales (DiLalla et al., 1996; 1999). The senior author on both MMPI papers was David DiLalla, Gottesman's former doctoral student and a contributor to this symposium; co-author Gregory Carey was also one of Gottesman's former students.

Like Gottesman, I (NS) was closely involved with the Minnesota Study of Twins Reared Apart (MISTRA) as a postdoctoral fellow (1982-1985) and research associate (1985-1991), as well as in the years that followed. In 2006, I launched the first prospective study of reared-apart twins adopted from China and completed several case reports of twins raised in different families.

The Fullerton Study of Chinese Twins Reared Apart came about in response to a Canadian mother who had adopted one MZ female twin from China and wrote to me in 2001 for information about raising a 'singleton twin'. In fact, China's one-child policy, enacted in 1979, led to the abandonment of hundreds of thousands of female infants; that policy and the cultural preference for male children are indirectly responsible for separating twins, mostly female (Segal, 2005; Segal et al., 2011). I have assessed 23 separated sets (21 from China and 2 from Vietnam) and completed follow-up visits for approximately half the sample. The twins' mean age at their first assessment was 9.60 years $(S D=6.48)$, and ranged between 3.19 and 24.98 years. Twins completed a general intelligence test, and their parents completed forms concerning their child's behavioral problems, medical life histories, family background, and other areas. Companion studies of adopted Chinese twins raised together (CTTs) and virtual twins (VTs; same-age unrelated children of all backgrounds raised together from birth) are also in progress.

Two papers from this ongoing research program concern twin relationships and developmental risks. A qualitative analysis of the Chinese twins' responses to their first meeting with, and first departure from, their co-twin found that twins older than 18 months of age displayed strong attraction toward one another, whereas younger twins showed more neutral reactions. Older twins also showed more intense reactions and greater upset than younger twins at the time of departure (Segal \& Marelich, 2011). This exploratory story included only the first 10 pairs; a more indepth analysis of the twins' social relationships is planned for the future. A second study combined CTTs and VTs in a study of developmental risks. Surprisingly, age at adoption added less than other predictors to adoptees' externalizing and internalizing behaviors. Family factors, such as parental education, contributed significantly to the behavioral outcomes of the CTTs. Comparing the resemblance of CTTs and VTs showed that genetic influence affected initial adaptation to adoption, refusal/avoidance, cying/clinging, and developmental delays $\left(r_{\mathrm{i}} \mathrm{s}=0.71-0.91\right)$, with shared environmental effects evident for the latter two measures (Segal, Tan et al., 2015).

I (NS) have completed four case reports of reared-apart twins, three MZAf pairs born in South Korea (Segal \& Cortez, 2014; Segal \& Hur, 2008; Segal, Hur et al., 2015) and one DZAf pair born in England (Segal, Cortez et al., 2015). Co-twins in all three MZAf pairs were raised in different countries (two in the United States and South Korea, and one in the United States and France). Despite the extremely different environments in which some of these 
co-twins were raised, some striking similarities in their behavioral and medical characteristics were observed. At the same time, differences in their mental abilities and personality traits were expressed that were possibly tied to events in their respective life histories. The co-twins in the DZAf pair both remained in England until one of the twins moved to the United States in her twenties. These twins, who were reunited at 78 years of age, have been entered into the Guinness World Records as the world's longest separated set $(G W R, 2016)$. As expected, given their $50 \%$ average genetic relatedness, these twins were less alike behaviorally than the member of the three MZAf pairs.

In 2012, I authored Born Together-Reared Apart: The Landmark Minnesota Twin Study, a book that surveyed the history and findings of the MISTRA (Segal, 2012). Gottesman was one of two prepublication reviewers, and on one Saturday morning, he spent several hours on the telephone with me commenting on various sections. I am confident that the book was significantly improved because of his perceptive eye.

\section{Twins Switched at Birth}

Twins switched at birth are identified very rarely, reflected in the fact that only nine cases have been documented worldwide. However, I strongly suspect that some twins are growing up either as singletons in the wrong family, or as VTs believing that are DZ. In fact, two independent medical companies estimated that between 20,000-23,000 misplacements of newborns occur each year in United States hospitals, but are quickly corrected (DNA Diagnostics Center, 2010; Rusting, 2001). However, given the very large number of potential errors, it seems unlikely that all such mistakes are rectified.

MZ twins would have an easier time learning if they had been exchanged because of their identical appearance in fact, instances of mistaken identity were responsible for revealing the truth in all nine cases. In 2011, I published a book covering the life events and behavioral similarities and differences of a switched-at-birth MZAf pair from Gran Canaria, Spain (Segal, 2011). These twins learned about the switch at age 28 when a family friend was certain that a clothing store customer was a woman she had known for some time.

Two of the nine cases involved a double exchange, that is, the switching of a newborn twin in one pair with a newborn twin in another pair. The first case, which occurred in Puerto Rico, involved an MZAf pair and an allegedly DZAf pair. In this case, the correct children were returned to their biological families when they were 18 months old. This was traumatic for the mother and father who were interviewed, given the strong parent-child attachments that had developed. However, a more striking case from Colombia, South America came to light in 2014 when it was discovered that a newborn MZAm twin in one
TABLE 2

Colombian Twins' Body Size Measures

\begin{tabular}{|c|c|c|c|c|c|c|c|}
\hline \multicolumn{8}{|c|}{ Visit 1, March-April 2015} \\
\hline & $\mathrm{cm}$ & $\mathrm{kg}$ & inches & $\mathrm{lb}$ & BMI & & \\
\hline City-1 & 170 & 66 & 66.9 & 145.5 & 22.84 & & \\
\hline Country-1 & 166 & 63.5 & 65.4 & 140.0 & 23.04 & & \\
\hline City-2 & 174 & 70 & 68.5 & 154.3 & 23.12 & & \\
\hline Country-2 & 172 & 68 & 67.7 & 149.9 & 22.99 & & \\
\hline \multicolumn{8}{|c|}{ Visit 2, July 2016} \\
\hline & $\mathrm{cm}$ & $\mathrm{kg}$ & inches & $\mathrm{lb}$ & Head L & Head W & $\mathrm{BMI}$ \\
\hline City-1 & 170 & 65.6 & 66.9 & 144.6 & 21.33 & 19.40 & 22.70 \\
\hline County-1 & 166 & 73 & 65.4 & 160.9 & 21.63 & 19.19 & 26.49 \\
\hline City-2 & 174 & 74.9 & 68.5 & 165.1 & 22.23 & 18.65 & 24.74 \\
\hline Country-2 & 172 & 68.5 & 67.7 & 151.0 & 21.25 & 18.20 & 23.15 \\
\hline
\end{tabular}

pair had been exchanged with a newborn MZAm twin in another pair. Again, the truth was revealed because of mistaken identity when the twins turned 25 . The following section expands upon selected aspects of these twins' physical and behavioral development. All four twins are shown in Figure 1.

\section{Zygosity}

The monozygosity of both twin pairs was confirmed by concordance across 21 short tandem repeat markers (STRs). However, it was of interest to apply Lykken's (1978) zygosity assessment formula, based upon fingerprint ridge count and body size; using these numbers, the probability of misclassification is less than $0.1 \%$. Kevin Haroian, who worked closely with Lykken, performed these calculations on data gathered from the twins in 2015 and 2016; the 2015 measures included height, weight, ponderal index and total fingerprint ridge count, while the 2016 measures additionally included the cephalic index and updated weight. The zygosity probabilities for the reared-apart twins and reared-together unrelated brothers are summarized in Tables 2 and 3.

Several findings are worth noting: First, Table 2 shows that one twin (Country-1) gained over 20 pounds (nearly $10 \mathrm{~kg}$ ) since the first visit (approximately 15 months earlier), increasing his BMI from 23.04 to 26.49 and widening the difference between himself and his co-twin. (His weight gain was due to intense working out at a gym and a dietary regimen of high protein drinks.) Most importantly, Table 3 shows that increasing the number of genetically informative traits in Lykken's formula generally increases the probability (and presumed accuracy) of twin-type classification. However, it also shows that the one twin's weight gain caused a substantial drop in the probability that he and his co-twin are MZ twins (87 to $47 \%$ ). Thus, the timing of such assessments can be critical - it is likely that the twins would have been diagnosed as DZ by the rules 


\section{TABLE 3}

Probability of Colombian Brothers' MZ Twinship Based on Fingerprint Ridge Count and Ponderal and Cephalic Indices in 2015 and 2016

\begin{tabular}{lllllll}
\hline Pairs & A-D (TRC) & Slater's Z & $\begin{array}{l}\text { Prob (\%) MZ } \\
\text { (TRC) 2015 }\end{array}$ & $\begin{array}{l}\text { Prob (\%) MZ } \\
\text { (TRC and Pl) 2015 }\end{array}$ & $\begin{array}{l}\text { Prob (\%) MZ } \\
\text { (TRC, Pl, Cl) 2016 }\end{array}$ & $\begin{array}{l}\text { Prob (\%) } \mathrm{MZ} \\
(\mathrm{TRC}, \mathrm{Pl}, \mathrm{Cl}) 2016^{\mathrm{b}}\end{array}$ \\
\hline MZA-1 & 12 & 0.65 & 71.4 & 84.2 & 87.1 & 47.7 \\
MZA-2 & 17 & 0.69 & 71.4 & 85.9 & 89.3 & 84.8 \\
VT-1 & 31 & 0.99 & 19.5 & 36.1 & 15.8 & 9.6 \\
VT-2 & 60 & 1.19 & 13.7 & 25.2 & 24.0 & 4.1 \\
\hline
\end{tabular}

Note: $\mathrm{A}-\mathrm{D}=$ absolute difference, $\mathrm{TRC}=$ total fingerprint ridge count, $\mathrm{PI}=$ ponderal index, $\mathrm{Cl}=$ cephalic index, $\mathrm{MZA}=\mathrm{MZ}$ reared-apart pair, $\mathrm{VT}=$ virtual twins (unrelated pair raised together)

${ }^{\text {a }} \mathrm{Cl}$ recorded in 2016; PI based on 2015 weight.

${ }^{b} \mathrm{Cl}$ recorded in 2016; PI based on 2016 weight.

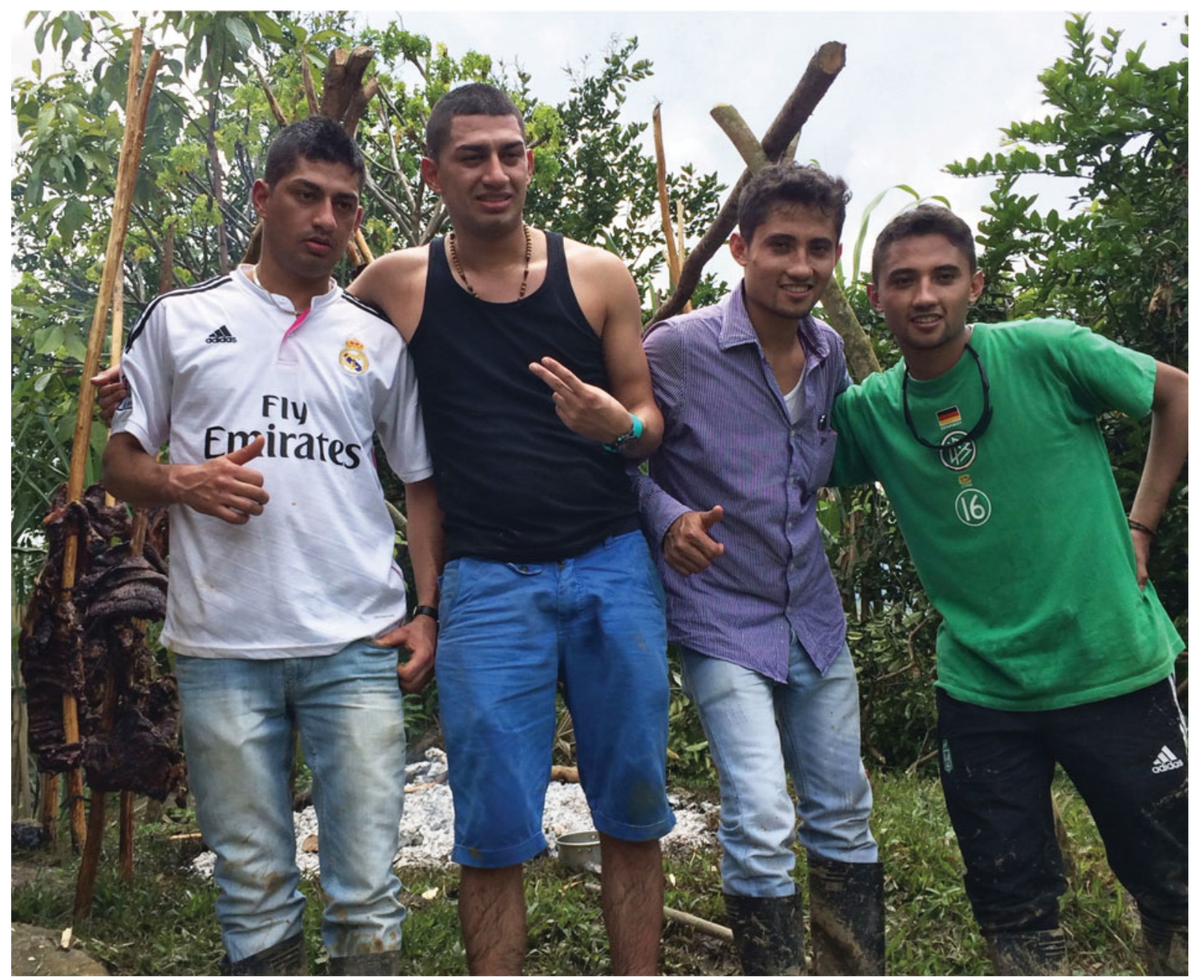

\section{FIGURE 1}

(Colour online) The four Colombian twins at a family gathering in the country, March 2015. The members of one MZA twin pair are the first and second from the left; the members of the other MZA twin pair are third and fourth from the left. Photo credit: Dr. Nancy L. Segal.

specified in Nichols and Bibro's (1966) physical resemblance questionnaire, a weight difference of 15 pounds or more is one index of dizygosity at the second level of certainty. Given the foregoing, the best method for zygosity diagnosis remains DNA analysis.

\section{Cognitive Development}

The twins completed both the WAIS-IV IQ test and the Raven Advanced Progressive Matrices (APM), Set-II (Raven, 1965). In the interest of confidentiality, general intelligence test results were summarized in general terms 


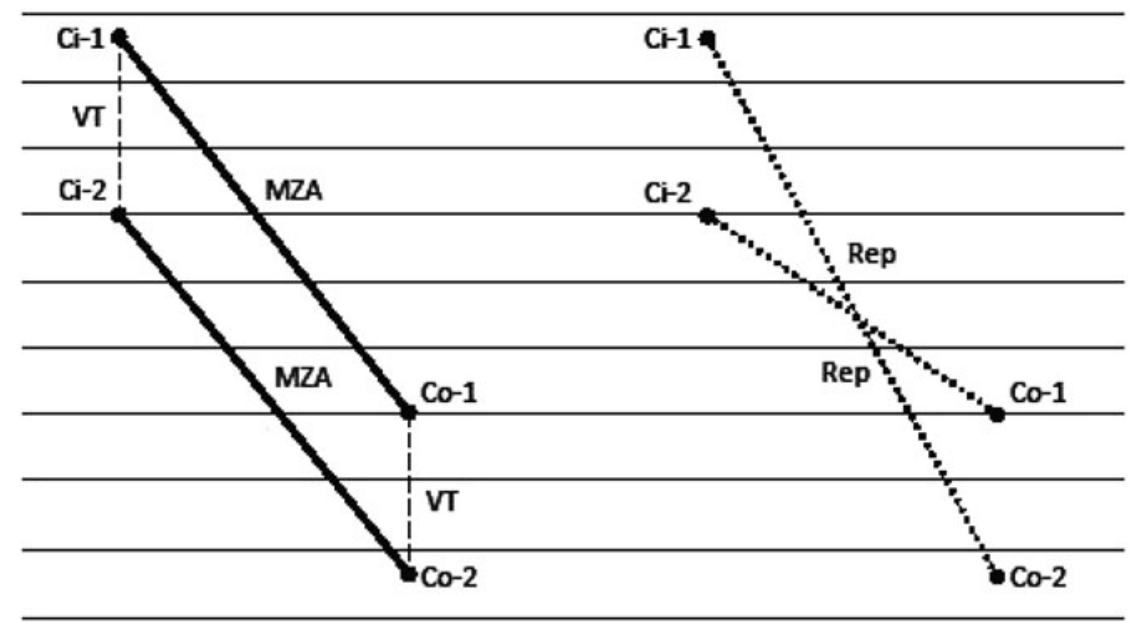

\footnotetext{
MZA = MZ reared-apart pair; C-1,2 = City-raised; Co-1,2 = Country-raised;

VT = Virtual Twin (same-age, unrelated);

Rep = Replica (replicates the Virtual Twins, but without the shared emvironment)
}

\section{FIGURE 2}

Colombian twins' performance on the Raven APM, Set II. Illustration credit: Kelly Donovan, BA.

by Segal and Montoya (2018). In brief, the city-raised twins outscored their country-raised co-twins, (who had not advanced beyond the fifth grade), with both similarities and differences noted in the profiles of the rearedapart twins and unrelated pairs. One set of replicas performed quite differently, while the other set showed unexpected resemblance in their profile pattern, although not in their level. These findings are of interest given the different life histories of the various pair members, but this single case does not challenge the $50-75 \%$ genetic influence on general intelligence, based upon years of twin and family research.

The Raven APM, Set II is a non-verbal multiple-choice test, devised in 1947 for officer selection. It assesses the ability to draw comparisons between figures and to develop a logical method of reasoning. The 36 items can be completed either with a time limit (capacity for observation and clear thinking) or without a time limit (efficiency of intellectual work). The twins completed only Set-II as a power test, without a time constraint, in order to reveal differences in what they knew and could do. Efforts were made to note the item on which they were working at $42 \mathrm{~min}$, given that approximately $40 \mathrm{~min}$ yields a satisfactory score distribution in group administrations. Instructions were reviewed carefully prior to testing.

The better educated city-raised twins outscored their country-raised co-twins. The co-twins in one MZA pair were at items 34 and 24, respectively, after $42 \mathrm{~min}$ had elapsed, whereas the co-twins in the other pair completed the test in less than $42 \mathrm{~min}$. Members of the unrelated pairs (VTs) scored closer to one another than to their rearedapart co-twins. Interestingly, the degree of difference between the two MZA pairs and the two VT pairs was about the same. The biggest difference among the six pairings was between one of the replicated pairs, followed by the two MZA twin pairs. These findings are shown graphically in Figure 2.

These results suggest that the twins' different educational backgrounds played a role in their performance, with the lack of education overwhelming the genetic potentials of the country-raised twins, and despite the general recognition of the Raven APM as a valid, non-verbal measure of mostly fluid intelligence (Kvist \& Gustafsson, 2008). General intelligence test scores for some twins in the MISTRA varied as a function of educational experience, but the effects were not systematic (Segal, 2012). In addition, Newman et al. (1937) found that educationally advantaged twins generally outperformed their less advantaged co-twins, but the intraclass correlations for both mental ability tests in that study remained high. The lower scores of the countryraised Colombian twins may partly reflect their lack of education, although as yet unknown factors (e.g., unfamiliarity with the test situation) may have played a role; the higher scoring country-raised twin had, in fact, obtained a GED in his early twenties. Interestingly, both large Raven and WAIS-IV discrepancies were noted for one reared-apart 
pair, whereas only a large Raven discrepancy was noted for the other pair.

\section{Twin-Family Study of Social Closeness}

On a different twin-related track, Gottesman applied the twin-family design to assess the risk of schizophrenia to the children of discordant MZ and DZ twin pairs (Gottesman \& Bertelsen, 1989). As I noted in the introduction to this special issue (and as Christensen and Bertelesen describe in their article), a key finding was that the offspring of discordant MZ twins were at equal risk for developing the disorder, whereas the offspring born only to affected DZ co-twins were at risk. The twin-family study (variously known as the MZ Half-Sibling Design, Nuclear Family Twin Design, Children-of-Twins Approach, and Twin-Pedigree Study) has been used to assess factors affecting a range of physical and behavioral traits, such as cognition (Van Leeuwen et al., 2008), age at menarche (Mendle et al., 2006), externalizing disorders (Hicks et al., 2004), and self-esteem (Bleidorn et al., 2018). My laboratory continues to use this model to compare the social closeness of MZ and DZ twin aunts and uncles expressed toward their nieces and nephews (Segal et al., 2007; Segal \& Marelich, 2011). Updated findings and future directions for this project have also been presented (Segal et al., 2016).

Participants from both intact and non-intact twin pairs ( $n=470$ individuals: $44 \mathrm{MZm}, 318 \mathrm{MZf}, 15 \mathrm{DZm}, 93 \mathrm{DZf}$; 6 male and 28 female twins were from opposite-sex twin pairs) completed a Social Closeness Survey, mostly online, although a minority of participants from the annual Twins Days Festival in Twinsburg, Ohio completed a pencil and paper version. Two major hypotheses, guided by evolutionary reasoning, were assessed: (1) MZ twin aunts/uncles will indicate greater social closeness toward their nieces and nephews than DZ twin aunts/uncles, and (2) twins with female co-twins will express greater social closeness toward their nieces and nephews than twins with male co-twins. Hypothesis 1 is derived from Hamilton's (1964) assertion that natural selection favors alleles predisposing individuals to act in ways that favor transmission of those alleles. Alleles predisposing individuals to behave altruistically toward others likely to carry copies of those alleles would be an indirect way of transmitting one's genes to future generations, thereby enhancing one's reproductive success (inclusive fitness). Hypothesis 2 drew upon the concept of paternity uncertainty, namely that because of hidden ovulation, internal fertilization and continuous female sexual receptivity, males cannot be certain that children delivered by their partner are truly theirs. Thus, greater social closeness should be expressed by uncles and aunts whose nieces and nephews were born to twin sisters, rather than to twin brothers.

Both hypotheses were supported by the data. The main effect for zygosity was significant, $F(1,466)=10.85, p=$ .001 , with lower scores reflecting increased social closeness.
Closeness toward nieces and nephews was greater for $\mathrm{MZ}$ twins $(M=22.26, S D=6.00)$ than for DZ twins $(M=25.81$, $S D=6.02)$.In addition, the main effect for co-twin sex was significant, $F(1,466)=17.26, p<.001$. As expected, closeness was greater for twins with female co-twins $(M=22.37$, $S D=5.09)$ than for twins with male co-twins $(M=26.45$, $S D=5.47)$. Not surprisingly, social closeness correlated significantly with perceived similarity: $r=0.58, p<.001$. This study is ongoing and can be completed online at https:// fullerton.qualtrics.com/jfe/form/SV_1XJDEwEaPIYEiyN.

\section{Acknowledgment}

Irving I. Gottesman may be gone, but he is not forgotten. His memory remains in the minds of everyone who knew him, and his work will be cited often in the years to come.

I wish to thank the members of this panel for their participation and their generosity. I also wish to thank Irv's University of Minnesota colleague, Dr. Bruce Overmeier, for launching an 'In Honor Of page for Irv, sponsored by the Federation of Associations in Behavioral and Brain Sciences (FABBS). Colleagues, friends, and people who may have known Irv just by his work are asked to consider making a donation of any size - all donations are welcome. Please visit http://fabbs.org/our_scientists/ irving-i-gottesman-phd/

\section{References}

Bleidorn, W., Hufer, A., Kandler, C., Hopwood, C. J., \& Riemann, R. (2018). A nuclear twin family study of selfesteem. European Journal of Personality. Advance online publication.

DiLalla, D. L., Carey, G., Gottesman, I. I., \& Bouchard, T. J. (1996). Heritability of MMPI personality indicators of psychopathology in twins reared apart. Journal of Abnormal Psychology, 105, 491-499.

DiLalla, D. L., Gottesman, I. I., Carey, G., \& Bouchard, T. J. Jr. (1999). Heritability of MMPI Harris-Lingoes and subtleobvious subscales in twins reared apart. Assessment, 6, 353366.

DNA Diagnostics Center. (2010, November 1). Identification techniques for preventing infant mix-ups. Retrieved from http://www.dnacenter.com/science-technology/articles/ infant-mix-up.

Gottesman, I. I., \& Bertelsen, A. (1989). Confirming unexpressed genotypes for schizophrenia: Risks in the offspring of Fischer's Danish identical and fraternal discordant twins. Archives of General Psychiatry, 46, 867-872.

Guinness World Records (GWR). (2016). Humans: Twins. (pp. 62-63). London, UK: Author.

Hamilton, W. D. (1964). The genetical evolution of social behavior. Journal of Theoretical Biology, 7, 1-52.

Hearnshaw, L. S. (1979). Cyril Burt, Psychologist. New York, NY: Cornell University Press.

Hicks, B. M., Krueger, R. F., Iacono, W. G., McGue, M., \& Patrick, C. J. (2004). Family transmission and heritability 
of externalizing disorders: A twin-family study. Archives of General Psychiatry, 61, 922-928.

Johnson, W., Bouchard, T. J., Krueger, R. F., McGue, M., \& Gottesman, I. I. (2004). Just one g: Consistent results from three test batteries. Intelligence, 32, 95-107.

Johnson, W., Turkheimer, E., Gottesman, I. I., \& Bouchard, T. J. (2009). Beyond heritability: Twin studies in behavioral research. Current Directions in Psychological Science, 18, 217-220.

Juel-Nielsen, N. (1965). Individual and environment: Monozygotic twins reared apart. New York, NY: International Universities Press.

Juel-Nielsen, N. (1980). Individual and environment: Monozygotic twins reared apart (revised edition). New York: International Universities Press.

Kendler, K. S., Thornton, L. M., \& Pedersen, N. L. (2000). Tobacco consumption in Swedish twins reared apart and reared together. Archives of General Psychiatry, 57, 886-892.

Kvist, A. V., \& Gustafsson, J. E. (2008). The relation between fluid intelligence and the general factor as a function of cultural background: A test of Cattell's investment theory. Intelligence, 36, 422-436.

Lykken, D. T. (1978). The diagnosis of zygosity in twins. Behavior Genetics, 8, 437-473.

Markon, K. E., Krueger, R. F., Bouchard, T. J. Jr., \& Gottesman, I. I. (2002). Normal and abnormal personality traits: Evidence for genetic and environmental relationships in the Minnesota study of twins reared apart. Journal of Personality, 70, 661-693.

Mendle, J., Turkheimer, E., D’Onofrio, B. M., Lynch, S. K., Emery, R. E., Slutske, W. S., \& Martin, N. G. (2006). Family structure and age at menarche: A children-of-twins approach. Developmental Psychology, 42, 533-542.

Newman, H. N., Freeman, F. N., \& Holzinger, K. J. (1937). Twins: A study of heredity and environment. Chicago, IL: University of Chicago Press.

Nichols, R.C., \& Bilbro, W. C. Jr. (1966). The diagnosis of twin zygosity. Acta Geneticae et Statistica Medicae, 16, 265-275.

Raven, J. C. (1965). Advanced progressive matrices, Set-II. Eynsham, Oxford, UK: Oxford Psychologists Press.

Rusting, R. R. (2001). Baby switching: An under-reported problem that needs to be recognized. Journal of Healthcare Protection Management, 17, 89-100.

Segal, N. L. (2005). Indivisible by two: Lives of extraordinary twins. Cambridge, MA: Harvard University Press.

Segal, N. L. (2011). Someone else's twin: The true story of babies switched at birth. Amherst, NY: Prometheus.

Segal, N. L. (2012). Born together - Reared apart: The landmark Minnesota twin study. Cambridge, MA: Harvard University Press.
Segal, N. L., \& Cortez, F. A. (2014). Born in Korea - adopted apart: Behavioral development of monozygotic twins raised in the United States and France. Personality and Individual Differences, 70, 97-104.

Segal, N. L., Cortez, F. A., Zettel-Watson, L., Cherry, B. J., Mechanic, M., Munson, J. E., ... Reed, B. (2015). Genetic and experiential influences on behavior: Twins reunited at seventy-eight years. Personality \& Individual Differences, $73,110-117$.

Segal, N. L., \& Hur, Y.-M. (2008). Reared apart Korean female twins: Genetic and cultural influences on life histories, physical and health-related measures, and behavioral traits. International Journal of Behavioral Development, 32, 542-548.

Segal, N. L., Hur, Y.-M., \& Graham, J. L. (2015). Korean twins reared apart: Genetic and cultural influences on behavior and health. Adoption Quarterly, 18, 291-310.

Segal, N. L., \& Marelich, W. D. (2011). Social closeness and gift giving by $\mathrm{MZ}$ and $\mathrm{DZ}$ twin parents toward nieces and nephews: An update. Personality and Individual Differences, 50, 101-105.

Segal, N. L., Mollova, S., Marelich, W. D., \& Preston, K. (2016, June-July). Does genetic relatedness affect social closeness toward nieces and nephews? A twin-family study. Paper presented at the Human Behavior and Evolution Society Conference, Vancouver, Canada.

Segal, N. L., \& Montoya, Y. S. (2018). Accidental brothers: The story of twins exchanged at birth and the power of nature and nurture. New York, NY: St. Martin's Press.

Segal, N. L., Seghers, J. P., Marelich, W. D., Mechanic, M., \& Castillo, R.(2007). Social closeness of monozygotic and dizygotic twin parents toward their nieces and nephews. European Journal of Personality, 21, 487-506.

Segal, N. L., Stohs, J. H., \& Evans, K. (2011). Chinese twin children reared apart and reunited: First prospective study of co-twin reunions. Adoption Quarterly, 14, 61-78.

Segal, N. L., Tan, T. X., \& Graham, J. L. (2015). Twins and virtual twins: Do genetic (as well as experiential) factors affect developmental risks? Journal of Experimental Child Psychology, 136, 55-69.

Shields, J. (1962). Monozygotic twins: Brought up apart and together. London, UK: Oxford University Press.

Shields, J. (1978). MZA twins: Their use and abuse. From Newman to Burt - A decline? Progress in Clinical and Biological Research, 24, 79-93.

Van Leeuwen, M., Van Den Berg, S. M., \& Boomsma, D. I. (2008). A twin-family study of general IQ. Learning and Individual Differences, 18, 76-88.

Zhou, B., Gao, W., Lv, J., Yu, C., Wang, S., Liao, C., ... Wang, H. (2015). Genetic and environmental influences on obesityrelated phenotypes in Chinese twins reared apart and together. Behavior Genetics, 45, 427-437. 